Thorax (1961), 16, 291.

\title{
RESPIRATORY INFECTIONS IN MYELOMATOSIS
}

\author{
BY \\ P. E. BALDRY AND J. E. ROYDS \\ From Ashford Hospital, Middlesex
}

(RECEIVED FOR PUbLiCATION AUGUSt 8, 1960)

Since myelomatosis was first described, diagnostic advances have made it progressively easier to recognize at increasingly early stages. Originally it could only be diagnosed in a patient who presented with symptoms referable to the bones and who had Bence-Jones protein in the urine. Later the introduction of radiology and the technique of needle marrow biopsy added to the knowledge of this disease and allowed earlier diagnosis. More recently, a study of changes in the plasma proteins and their electrophoretic pattern in this disease has made it possible to diagnose it before bone changes and their associated symptoms become apparent. Such patients may present for investigation because of one or more of the following clinical pictures: Persistent anaemia, increasing weight loss (Brownell, 1955), nephritis (Bayrd and Heck, 1947), uraemia (Snapper, Turner, and Moscovitz, 1953), peripheral neuropathy (Clarke, 1956), primary amyloidosis (Lichtenstein and Jaffe, 1947; Hellier, 1959), and respiratory infections (Lawson, Stuart, Paull, Phillips, and Phillips, 1955).

We have been particularly interested over the past few years in patients with myelomatosis who have presented at this hospital with respiratory infections before symptoms referable to bone changes have become apparent. In some cases the disease has been recognized by the chance finding on a chest radiograph of characteristic bone changes in ribs or clavicles or spine ; in others it has been recognized because it is our practice, in any respiratory infection associated with anaemia, a normal white count, and a high E.S.R., to estimate the plasma proteins and study their electrophoretic pattern. At this hospital from 1951 to 1959 inclusive there have been 20 patients with myelomatosis. Nine presented with bone pain alone, of whom six had back pain and three pain due to the disease in other bones. One came under investigation for persistent weight loss, and the remaining 10 presented with symptoms referable to the chest. Two of these were admitted because of chest pain which on further analysis was found to be angina of effort due to the anaemia associated with this disease. One was admitted with pulmonary tuberculosis, and while under treatment was found to have myelomatosis. The remaining seven patients presented with an acute respiratory infection, or gave a history of having had one recently.

It is the purpose of this paper to describe these seven patients and to discuss the significance of respiratory complications in this disease. In the case reports only details of the pulmonary infections and the steps which led to the diagnosis of the underlying myelomatosis will be given. Other features will be omitted, as several excellent general reviews of this disease have already been published (Geshickter and Copeland, 1928; Atkinson, 1937 ; Bayrd and Heck, 1947 ; Lichtenstein and Jaffe, 1947; Adams, Alling, and Lawrence, 1949 ; Snapper et al., 1953 ; Brownell, 1955 ; Dancaster, Hussain, and Jackson, 1959).

\section{CASE REPORTS}

CASE 1.-Mr. S. C., aged 49, was admitted on January 12, 1953, with severe lumbar pain for seven weeks, having had two pneumonic episodes treated at home, three months and two months previously. Investigations showed: Hb $51 \%$, W.B.C. 9,600/c.mm., B.S.R. $64 \mathrm{~mm}$. in 20 minutes. Radiographs of the lumbar spine showed osteoporosis and compression of the vertebrae. Plasma proteins were therefore estimated. On January 15 the total proteins were 11.1 g. $\%$ (albumin 1.1 g. $\%$, globulin 10 g. $\%$ ) and blood urea $87 \mathrm{mg} . \%$ Albumin, but no Bence-Jones protein, was found in the urine. Examination of bone-marrow on January 20 showed $28.6 \%$ proplasmacytes and $35 \%$ plasmacytes (normal 0.0-2.0). He was discharged on February 25, 1953. During readmissions until July 7, 1953, there were no further pneumonic episodes. After this he was treated at home and no record of his progress is available.

CASE 2.-Mr. F. J., aged 52, was admitted on September 19, 1955, with pain in the chest for eight weeks. Two days previously he had suddenly developed fever, lyspnoea, and cough with purulent 
and blood-stained sputum. On admission he was very ill with a high fever $\left(104^{\circ}\right)$ and physical signs of bronchopneumonia with a pleural effusion. A chest radiograph confirmed these findings. Sputum culture gave a heavy growth of pneumococci. $\mathrm{Hb}$ was $77 \%$, E.S.R. $41 \mathrm{~mm} . /$ one hour, W.B.C. $5,000 /$ c.mm. (57\% polymorphs, $38 \%$ lymphocytes, and $4 \%$ plasma cells). He was treated with penicillin, 2 mega units a day, for four days combined with streptomycin $\frac{1}{2}$ g. six-hourly for the first 48 hours. This was followed by chloramphenicol $250 \mathrm{mg}$. six-hourly for a further six days. At the end of this initial 10 days the fever had gradually subsided. A chest radiograph on September 28, however, showed no improvement and in addition a lateral view showed collapse of the ninth and eleventh dorsal vertebrae. At first these changes were thought to be due to metastases, but estimation of the plasma proteins showed total proteins 7.9 g. \% (albumin 2.2 g. \% and globulin 5.7 g. \%) and the electrophoretic pattern showed a well-defined gamma globulin band. In view of this finding the bone-marrow was examined on October 11 and showed $21.6 \%$ proplasmacytes and 2.8 plasmacytes. The only bone of which a radiograph was taken was the skull, which showed numerous small round translucencies.

On October 12 he had a sudden rigor with fever up to $104^{\circ}$; blood culture gave a growth of pneumococci. He responded well to 1 mega unit of penicillin intramuscularly four times a day. This was continued for three weeks. Further pneumonic episodes occurred on November 6 and November 18. He took his own discharge on December 14 and there is no further record of his progress available.

CASE 3.-Mr. A. T., aged 57, was admitted on December 3, 1955, with a history that in January, 1955 , he had a severe respiratory infection with cough and blood-stained sputum. This recurred in September. In November he began to cough up blood intermittently and for three weeks before admission there was blood in his sputum most of the time. In addition, he had been easily tired for about six months with intermittent low back pain.

On admission he looked ill, temperature $102^{\circ}$, with much purulent blood-stained sputum. Numerous crackling sounds were heard over the front and back of the right side of chest.

Haemoglobin was $44 \%$, W.B.C. $8,800 /$ c.mm. and E.S.R. $77 \mathrm{~mm}$./one hour. A chest radiograph showed collapse with consolidation of the middle lobe and the apical segment of the right lower lobe, and also much hilar calcification. Bronchoscopy and bronchography showed stenosis of the middle lobe orifice. This was therefore an example of recurrent infection in a permanently damaged middle lobe due to post-tuberculous bronchostenosis (the middle lobe syndrome). In addition the ribs on this chest radiograph showed a few small translucencies suggestive of myelomatous deposits (Fig. 1). For this reason, together with the blood changes, the plasma proteins were estimated on December 29. Total proteins were

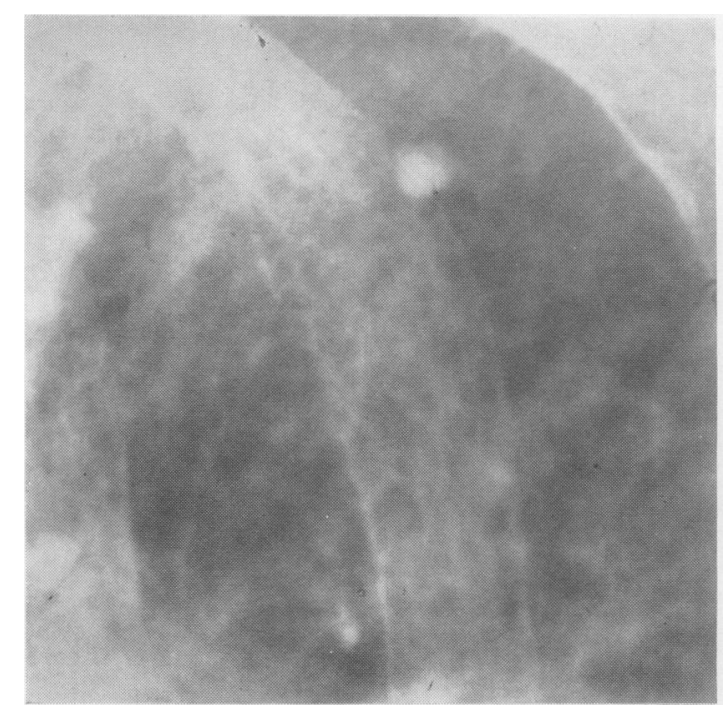

FIG. 1.-Punched-out areas in ribs seen near to diffuse shadowing in lung.

10.7 g. $\%$ (albumin 2.6 g. \%, globulin 8.1 g. \%). The electrophoretic pattern showed a well-defined gamma globulin band. The urine contained a large amount of Bence-Jones protein. Bone-marrow examination on January 3 showed $13.2 \%$ plasmacytes. Radiographs of the lumbar spine on January 6 showed come pression fractures in the bodies of the second and fourth lumbar vertebrae. The pulmonary infection persisted in spite of 1 mega unit of penicillin a day intramuscularly, and after the third day it was shown by sputum culture that the causative organism was Haemophilus influenzae sensitive to tetracycline. After changing to this antibiotic the infection quickly subsided. The patient was discharged on January 24 After this no further respiratory infections occurred, but the patient's general condition deteriorated and he died on May 14, 1957.

CASE 4.-Mrs. N. B., aged 59, was admitted on April 24, 1956, with a history of losing weight for nine months, increasing dyspnoea for three months, and three weeks previously she had been admitted to another hospital because for four days she had had fever, cough with yellow sputum, and marked increase of shortness of breath. There were pneumonic changes at both lung bases on physical examination, confirmed by a radiograph. In addition, the chest film showed healed tuberculous scars at the left apex. The pneumonia cleared satisfactorily with penicillin, but she was found to be anaemic ( $\mathrm{Hb} 72 \%$ ). As her only relative lived in our area she was transferred here for further investigations. Our chest radiograph showed tuberculous scarring at the left apex and also showed punched-out translucent areas in both clavicles. The possibility of myelomatosis was therefore considered. Investigations showed: $\mathrm{Hb} 66 \%$, W.B.C. 7,400/c.mm., E.S.R. $64 \mathrm{~mm}$./one hour, total 


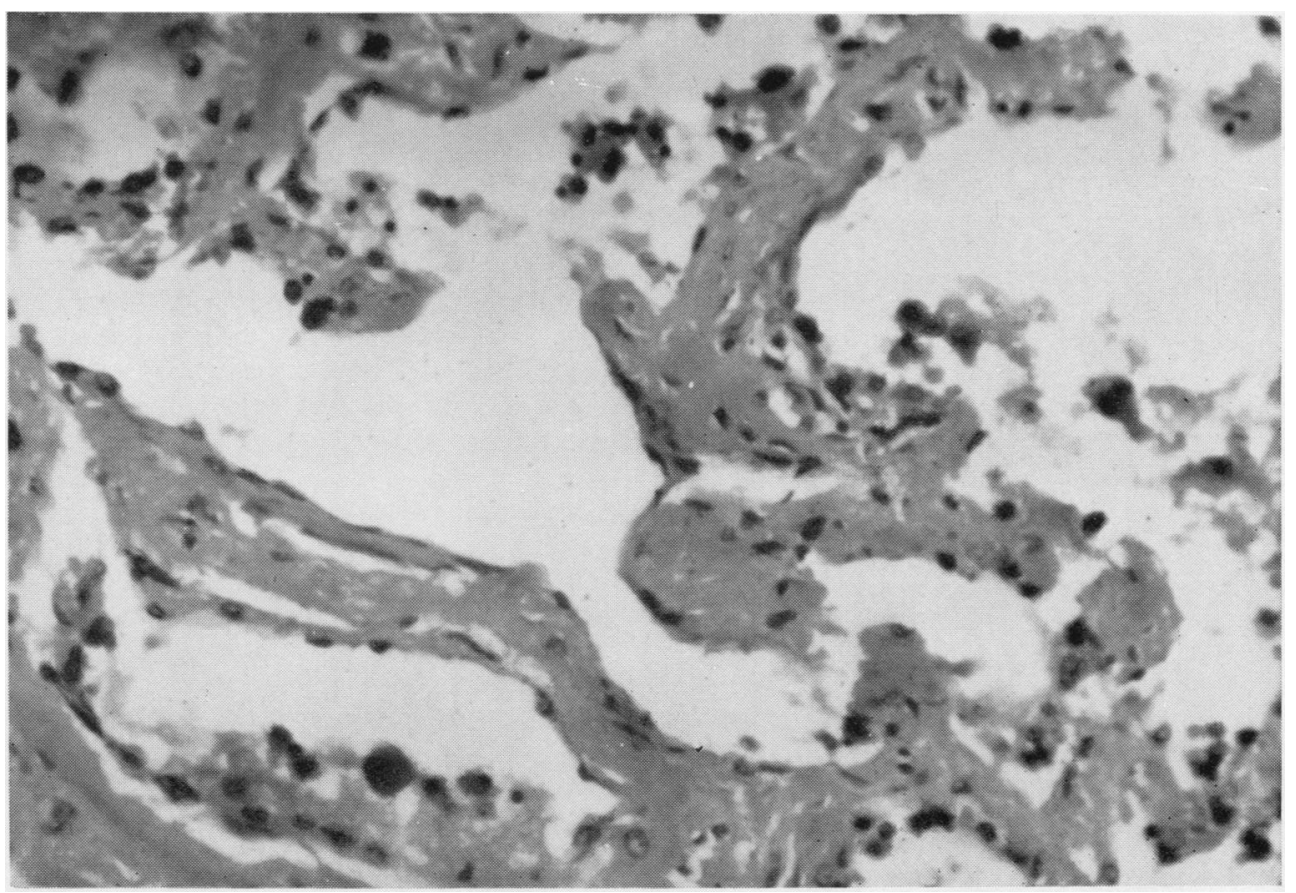

Fig. 2.-Amyloid material in thickened alveolar septa.

plasma proteins 6.8 g. \% (albumin 3.3 g. $\%$ and globulin 3.5 g. $\%$ ). The electrophoretic pattern showed no abnormality. There was no Bence-Jones protein but much albumin in urine. The blood urea level was $152 \mathrm{mg} . \%$ Sternal puncture on two occasions failed to produce bone-marrow. She was discharged on May 23, 1956, readmitted on June 11 with a terminal bronchopneumonia, and died on June 13. Necropsy showed myelomatous changes in the skull, clavicles, and bone-marrow from the sternum. In addition, there was an unusual finding in the lungs of very thickened alveolar septa with deposits of palely stained eosinophilic material due to widespread amyloidosis (Fig. 2).

CASE 5.-Mrs. A. F., aged 59, attended as an outpatient on June 16,1958 , with a pain in the left side of the chest of two weeks' duration. She had been losing weight, feeling easily tired, and had a poor appetite for six months. She had a long-standing cough with sputum attributed to smoking 20 cigarettes a day. A chest radiograph (Fig. 3) showed an area of pneumonia at the left base and two linear wedgeshaped areas of atelectasis in the right lung: on the postero-anterior view one ran horizontally just above the lesser fissure and the other in a diagonal direction below it. These shadows cleared rapidly. Haemoglobin was $50 \%$, W.B.C. $8,700 /$ c.mm., E.S.R. $60 \mathrm{~mm}$./one hour. She had heavy albuminuria. In view of the pneumonia, high E.S.R., and normal white count, the plasma proteins were estimated to exclude a collagen disease or myelomatosis. Total proteins on June 20 were $9.4 \mathrm{~g} . \%$ (albumin $4.5 \mathrm{~g}$. \%, globulin $4.9 \mathrm{~g} . \%$ ). The electrophoretic pattern showed a well-

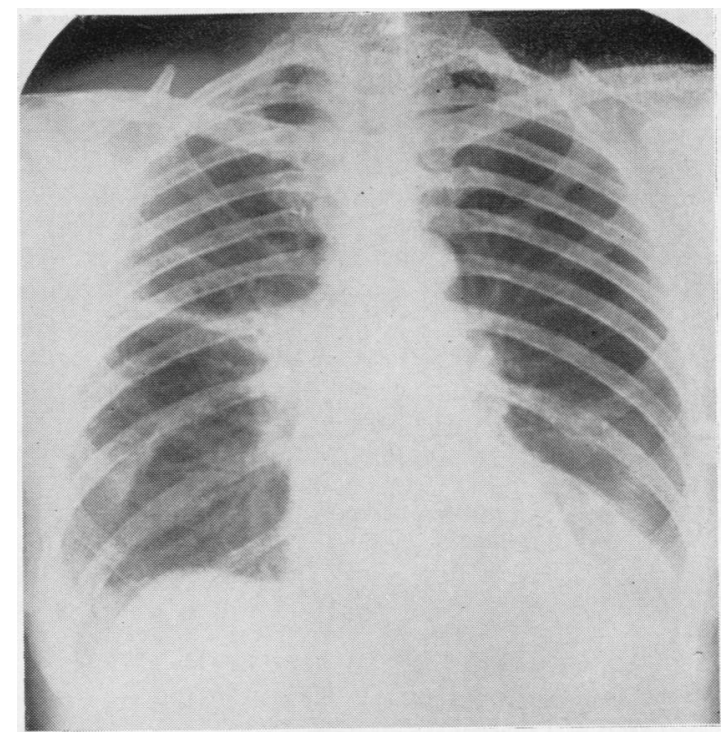

FIG. 3.-Case 5. Chest radiograph 2.6.58. Shadowing seen at the left base, and two linear wedge-shaped areas on the right suggesting atelectasis, the lower being in a diagonal direction. 
defined $M$ band, and at this stage there was BenceJones proteinuria. Bone-marrow showed a marked increase in plasma cells, but there were no radiological changes in the bones. She had no further pulmonary infective episodes until a bronchopneumonia just before she died on January 24, 1960.

CASE 6.--Mrs. C. B., aged 70, was admitted on November 27, 1958, having had a left-sided pneumonia treated at home in September, 1958. Four days before admission there had been a recurrence on the right side. Her temperature was $102^{\circ}$ with a pneumonia involving the right lower lobe as shown by physical signs. A chest radiograph confirmed this and also showed two horizontal wedge-shaped areas of linear atelectasis in the right lung; the heart shadow was enlarged. Sputum culture gave a profuse growth of Strep. viridans with a lesser growth of Strep. pneumoniae. Haemoglobin was $53 \%$, W.B.C. $6,500 /$ c.mm. ( $62 \%$ polymorphs), E.S.R. $25 \mathrm{~mm}$./one hour. The infection responded readily to a course of tetracycline but the anaemia persisted, and on December 13 the E.S.R. had risen to $75 \mathrm{~mm}$./one hour. For this reason plasma proteins were estimated on December 17. Total proteins were $11 \mathrm{~g} . \%$ (albumin 2.4 g. $\%$ and globulin 8.6 g. \%). The electrophoretic pattern showed a well-marked gamma band. She had slight albuminuria but no Bence-Jones proteinuria. The blood urea level was $29 \mathrm{mg}$.'. Bone-marrow examination on December 19 showed $8.8 \%$ plasmacytes. Radiography of the skull and long bones at this stage showed no abnormality. She was discharged on January 7, 1959. She was readmitted on September 4 with fever and physical signs and radiographic appearances of bronchopneumonia. This cleared readily with a further course of tetracycline with return of the temperature to normal in four days. However, the haemoglobin remained between 40 and $50 \%$ in spite of repeated blood transfusions. Radiographs on September 14, 1959, now showed widespread myelomatous deposits in the skull, humerii, radii, one femur, both clavicles, and several vertebrae. At this stage there was Bence-Jones protein in the urine with a blood urea level of $112 \mathrm{mg} .{ }^{\prime} \circ$. The patient deteriorated and died on November 27, 1959.

CAse 7.-Mrs. V. S., aged 62, in February, 1959. was under treatment by her doctor for pneumonia. After this, pain persisted in the right side of the chest and she noted increasing shortness of breath on exertion, with persistent tiredness. A chest radiograph on May 27 was normal. She attended as an outpatient here on July 22. A chest radiograph showed the lungs to be clear but many small translucent areas in ribs. Radiographs of the skull, pelvis, and femurs showed similar changes. Haemoglobin was $60 \%$, W.B.C. $4,600 /$ c.mm. $(70 \%$ polymorphs), E.S.R. $55 \mathrm{~mm}$./one hour. Total plasma proteins were 8.6 g. \% (albumin 3.5 g. $\%$, globulin $5.1 \mathrm{~g} . \%$ ). The electrophoretic pattern showed a wellmarked $M$ band. There was a trace of albumin in the urine but no Bence-Jones protein. Examination of bone-marrow on July 19 showed a definite increase of plasma cells, of which a fair proportion were abnormally immature forms (proplasmacytes $2.8^{\prime \prime} \mathrm{o}$. plasmacytes $7.6 \%$ ). She has been followed since then without having any further respiratory infections.

(All blood sedimentation rates were estimated by the Westergren method.)

\section{RECURRENT RESPIRATORY INFECTIONS. -} Geshickter and Copeland in 1928 reviewed 425 cases of myelomatosis reported up to that time and added 13 cases of their own. They drew attention to the frequency of bronchitis and pneumonia in these patients. The disease, however, in those days was diagnosed at a stage when there were extensive bone changes. The pain of rib involvement, fractures of ribs, sunken sternum. and dorsal kyphosis were all factors which interfered with movement of the chest wall. They felt that this impaired ventilation, together with the debilitated state and hypostatic changes dependent on long periods of best rest, contributed to the high incidence of respiratory infections. Bayrd and Heck, in 1947, reviewed the cases seen up to that time at the Mayo Clinic. None of their patients presented with pneumonia and, in fact. they found that pulmonary infection occurred no more frequently than may be expected in a group of debilitated persons. Pneumonia also was not a feature in 61 proved cases of myelomatosis reviewed by Brownell in 1955. On the other hand, pneumonia occurred at some stage in the illness in $45 \%$ of 40 cases reviewed by Dancaster et al. (1959). Symptoms referable to the lungs occurred in $50 \%$ of 97 cases reviewed by Snapper et al. (1953). Twenty-four per cent. had at least one episode of pneumonia during their illness exclusive of terminal pneumonia: 13 had recurrent pneumonia and several had five or six infective episodes within two years.

In this series of 20 cases, excluding terminal bronchopneumonia, no acute respiratory infections occurred in 13 patients: in the remaining seven patients who are the subject of this paper, excluding terminal bronchopneumonia, one had four episodes (Case 2), three had two episodes (Cases $1,3,6)$, and three had a single episode (Cases 4 , 5, and 7).

Plasma Proteins.- - It has been observed that in myelomatosis recurrent pneumonia occurs most frequently with greatly raised serum globulin levels. At first sight this might seem surprising in view of the fact that it is well known that normal gamma globulins contain antibodies, and that in other diseases where the gamma globulins are raised there is no increased susceptibility to infec- 
tion. It is now widely accepted that antibodies are formed mainly in plasma cells. Fagraeus (1948) demonstrated that in rabbits sensitized to horse serum, hyperglobulinaemia with an increase of antibodies developed concomitantly with a proliferation and maturation of plasma cells. In addition, much knowledge about the role of plasma cells in the production of antibodies has been gained by a study of children with the congenital condition of agammaglobulinaemia. The condition was first described by Bruton (1952) and since has been intensively studied, especially by Janeway and Gitlin (1957) and by Good and Zak (1956). In these children, who develop repeated bacterial infections, the almost complete absence of gamma globulins with a corresponding lack of antibodies is not due to excessive breakdown of the protein, as injected gamma globulin survives for a normal time (Good and Zak, 1956). The defect appears to be one of production and this is associated with a remarkable absence of plasma cells from the tissues. It was pointed out as long ago as 1937 by Bing and Plum that an increase of plasma cells is a feature common to various diseases with hyperglobulinaemia. Such a plasmacytosis in the marrow may be found in all diseases in which hyperglobulinaemia is common, such as systemic lupus erythematosus, Boeck's sarcoidosis, hepatic cirrhosis, or kala-azar. The important difference, however, is that in these other diseases the plasma cells are normal cells capable of producing normal gamma globulins with normal antibodies, whereas in myelomatosis the plasma cell has a morphologically distinct character and it is believed that these atypical plasma cells are responsible for the elaboration of abnormal serum proteins (Magnus-Levy, 1933, 1938). The abnormal globulin in myelomatosis in contrast to that seen in hyperglobulinaemia in other diseases appears as a high sharp spike on the electrophoretic pattern. Gutman, Moore, Gutman, McClellan, and Kabat (1941) and Gutman (1948) have shown that there are four major electrophoretic patterns which characterize myeloma sera: (1) A large component with the mobility of normal gamma globulin; (2) a definite increase in the fraction which moves with the speed of normal beta globulin; (3) a component with a mobility slower than normal beta globulin but faster than gamma globulin, designated by Moore, Kabat, and Gutman (1943) as the M component ; (4) a pattern with no characteristic change from normal.

The main difference between the abnormal globulins found in myelomatosis and those found in other diseases with hyperglobulinaemia is the markedly decreased content of antibodies in myelomatosis. Marks, in 1953, studied antibody formation in myelomatosis and compared it with that found in patients with hyperglobulinaemia from other causes and with normal controls. $\mathrm{He}$ found that, in diseases characterized by excess of qualitatively normal globulin in which the plasma cell formation is stimulated and not disordered, antibody formation is normal. The deranged growth of plasma cells in myelomatosis appears to be frequently associated with abnormal serum globulin and depressed antibody formation. Further work has been done on this subject by Lawson et al. (1955), who noticed that myelomatous patients were subject to repeated respiratory infections. Because of these observations a study of antibody production was undertaken by them and compared with that in normal persons and patients with diseases other than myelomatosis. They confirmed that a complete absence of antibodies or a marked deficiency of these substances is a characteristic feature of myelomatosis. They concluded that they knew of no other disease except agammaglobulinaemia in which a comparable deficiency of antibodies occurs.

Sluggish Pulmonary Circulation.-Snapper et al. (1953) discuss the possible additional factor of a sluggish pulmonary circulation to make these patients prone to respiratory infections. This is related to the high serum globulin with the tendency to rouleau formation of the red cells and an increased blood viscosity. The blood viscosity in some cases of myelomatosis has been reported to be higher than in any other condition (Albers, 1937 ; Magnus-Levy, 1933 ; Waldenström, 1952). Snapper et al. point out that this condition of pulmonary stasis is ideal for the production of small pulmonary infarctions which then may become secondarily infected and simulate recurrent bronchopneumonic episodes. In our series, Cases 5 and 6 had chest radiographs which, in addition to showing widespread shadowing associated with areas of pneumonitis, also showed transitory wedge-shaped areas of linear atelectasis, which might have been due to small areas of infarction.

Pre-myelomatosis.- It is now known that the characteristic changes in gamma globulin may occur in this disease some months or even years before the symptoms and signs of bone involvement. Bayrd and Heck (1947) state that the condition was diagnosed in $12 \%$ of their cases before 
any abnormality of bone could be demonstrated by radiological examination (this included radiographs of the head, thorax, and spinal column in all, and, in two-thirds, every bone). Therefore, patients who have myelomatosis with altered globulins may develop respiratory infections some time before symptoms or radiological evidence of bone involvement has developed. For this reason the possibility of the disease should be considered in any patient with recurrent pneumonic episodes, or where the pneumonia is accompanied by an anaemia, a normal white count, and a markedly elevated E.S.R. Cases 5 and 6 in our series are examples of this.

In Cases 2 and 4, although there were no skeletal symptoms at the time of respiratory infection, there were radiological changes to be observed in bones on the chest radiograph. In Case 2 the ninth and eleventh dorsal vertebrae had collapsed, and in Case 4 sharply demarcated translucent areas were seen in the clavicles.

\section{SUMMARY}

Twenty patients with myelomatosis have been seen at this hospital from 1951 to 1959 inclusive. Excluding terminal bronchopneumonia, seven cases have had one or more episodes of respiratory infection. Details of these are given. Some reasons for the susceptibility of myelomatous patients to pneumonia are discussed, in particular the changes in the plasma globulin. It is stressed that globulin changes with associated loss of resistance to infection may occur months or years before the symptoms and signs of bone involvement. It is necessary therefore in all cases of recurrent pneumonia or in a case of pneumonia with anaemia and a markedly elevated E.S.R. to exclude myelomatosis.

We would like to thank our colleagues, Dr. A. Barham Carter and Mr. F. G. Ward, for permission to study their cases.

\section{REFERENCES}

Adams, W. S., Alling, E. L., and Lawrence, J. S. (1949). Amer. J. Med., 6, 141 .

Albers, D. (1937). Z. klin. Med., 132, 807.

Atkinson, F. R. B. (1937). Med. Press, 195, 327.

Bayrd, E. D., and Heck, F. J. (1947). J. Amer. med. Ass., 133, 147.

Bing, J., and Plum, P. (1937). Acta med. scand., 92, 415.

Brownell, E. G. (1955). A.M.A. Arch. intern. Med., 95, 699.

Bruton, O.C. (1952). Pediatrics, 9, 722.

Clarke, E. (1956). Neurology, 6, 146.

Dancaster, C. P., Hussain, O. A. N., and Jackson, W. P. U. (1959). Postgrad. med. J., 35, 662.

Fagraeus, A. (1948). Acta med. scand., 130, Suppl. 204.

Geshickter, C. F., and Copeland, M. M. (1928). Arch. Surg. (Chicago), $16,807$.

Good, R. A., and Zak, S. J. (1956). Pediatrics, 18, 109.

Gutman, A. B. (1948). Advanc. Protein Chem., 4, 155. Moore, D. H., Gutman, E. B., McClellan, V., and Kabat, E. A. (1941). J. clin. Invest., 20, 765 .

Hellier, F. F. (1959). Brit. J. Derm., 71, 61.

Janeway, C. A., and Gitlin, D. (1957). Advanc. Pediat., 9, 65.

Lawson, H. A., Stuart, C. A., Paull, A. M., Phillips, A. M., and Phillips, R. W. (1955). New Engl. J. Med., 252, 13.

Lichtenstein, L., and Jaffe, H. L. (1947). Arch. Path. (Chicago), 44, 207.

Magnus-Levy, A. (1933). Z. klin. Med., 126, 62. (1938). Acta med. scand., 95, 217.

Marks, J. (1953). J. clin. Path., 6, 62.

Moore, D. H., Kabat, E. A., and Gutman, A. B. (1943). J. clin. Invest., 22, 67.

Snapper, I., Turner, L. B., and Moscovitz, H. L. (1953). Multiple Myeloma. Grune and'Stratton, New York.

Waldenström, J. (1952). Advanc. intern. Med., 5, 398. 